Illinois State University

ISU ReD: Research and eData

Theses and Dissertations

3-20-2014

\title{
Effects of Graston Technique on blood flow in the upper extremity
}

Ashley Nicole Keck

Illinois State University, ankeck@ilstu.edu

Follow this and additional works at: https://ir.library.illinoisstate.edu/etd

Part of the Kinesiology Commons, and the Physical Therapy Commons

\section{Recommended Citation}

Keck, Ashley Nicole, "Effects of Graston Technique on blood flow in the upper extremity" (2014). Theses and Dissertations. 107.

https://ir.library.illinoisstate.edu/etd/107

This Thesis is brought to you for free and open access by ISU ReD: Research and eData. It has been accepted for inclusion in Theses and Dissertations by an authorized administrator of ISU ReD: Research and eData. For more information, please contact ISUReD@ilstu.edu. 
EFFECTS OF GRASTON ${ }^{\circledR}$ TECHNIQUE ON BLOOD FLOW IN THE UPPER EXTREMITY

Ashley N. Keck

38 Pages

May 2014

Context: When musculature around the shoulder is tight, alterations in scapular positioning may result, thus compressing the blood vessels to the upper extremity and decreasing blood flow. Graston Technique (GT) mobilizes the soft tissues to break up adhesions in fascia and lengthens tight musculature. The effect of GT has on blood flow after treatment to the shoulder musculature is unknown. Objective: To determine if GT has an effect on blood flow and pectoralis minor length after a single treatment session. Design: Controlled laboratory study with randomization. Setting: University athletic training laboratory. Patients or Other Participants: Sixty healthy subjects ( 27 male, 33 female, age $=21.89 \pm 1.83$ years, height $=$ $173.01 \pm 9.26 \mathrm{~cm}$, weight $=72.13 \pm 12.86 \mathrm{~kg}$ ) volunteered to participate. Interventions: Each participant attended one testing session lasting approximately 30 minutes. Participants were randomly placed into 1 of 3 groups: control, sham, or GT. Blood flow in two positions and pectoralis minor length were measured. The dominant arm was used for all participants. Each participant then performed a 5 minute warm-up on an arm bike. The warm-up was followed by the assigned intervention and pectoralis minor stretching. Main Outcome Measure(s): Pectoralis minor muscle length and blood flow in a resting and provocative overhead position were measured at baseline and after intervention. Results: No significant differences between 
groups for all variables were found ( $p>0.05)$. Conclusions: A single treatment of GT did not produce a significant increase in the blood flow in the brachial artery in the dominant arms of a healthy population. This single treatment of GT combined with a gross stretch of the pectoralis minor also did not produce a significant increase in linear length of the pectoralis minor. Key Words: Instrument assisted soft tissue mobilization, manual therapy, overhead athlete, pectoralis minor length, vascular changes. 
EFFECTS OF GRASTON ${ }^{\circledR}$ TECHNIQUE ON BLOOD FLOW IN THE UPPER EXTREMITY

ASHLEY N. KECK

A Thesis Submitted in Partial

Fulfillment of the Requirements

for the Degree of

MASTER OF SCIENCE

School of Kinesiology and Recreation

ILLINOIS STATE UNIVERSITY

2014 
(C) 2014 Ashley N. Keck 
EFFECTS OF GRASTON ${ }^{\circledR}$ TECHNIQUE ON BLOOD FLOW IN THE UPPER EXTREMITY

ASHLEY N. KECK

COMMITTEE MEMBERS:

Justin M. Stanek, Chair

Noelle Selkow 


\section{ACKNOWLEDGMENTS}

I would like to thank my committee, Drs. Justin Stanek and Noelle Selkow who helped guide me through this process and devoted personal time to helping me complete this project. I would also like to thank Kelly Boyce who assisted with data collection and took valuable personal time to assist me. Finally, none of this would be possible without the continued support from my fiancé, his family, and my family.

A. N. K. 


\section{CONTENTS}

ACKNOWLEDGMENTS

CONTENTS

TABLES iv

CHAPTER

I. EFFECTS OF GRASTON ${ }^{\circledR}$ TECHNIQUE ON BLOOD FLOW IN THE UPPER EXTREMITY

Introduction 1

Methods 3

Participants 3

Procedures 3

Instrumentation 4

Pectoralis Minor Length Measurement $\quad 4$

Blood Flow Measurement 5

Interventions

Pectoralis Minor Stretch $\quad 6$

Blinding of Investigators $\quad 6$

$\begin{array}{ll}\text { Statistical Analysis } & 6\end{array}$

Results

Discussion 9

$\begin{array}{lr}\text { Conclusion } & 12\end{array}$

II. REVIEW OF RELATED LITERATURE

$\begin{array}{ll}\text { Bony Anatomy } & 13\end{array}$

Bony Articulations $\quad 15$

Soft Tissue Structures 16

Microanatomy of Muscle and Tendon $\quad 19$

$\begin{array}{ll}\text { Improving and Maintaining Flexibility } & 21\end{array}$

Mechanics and Healing 23

Manual Therapy 25

Graston Technique $\quad 27$

Vascular Adaptations in the Shoulder $\quad 30$ 
REFERENCES 


\section{TABLES}

Table

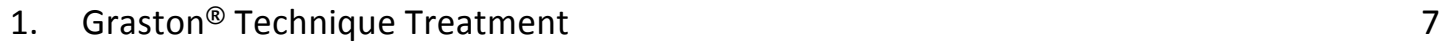

2. Pectoralis Minor Length Changes between Groups (mean \pm SD in $\mathrm{cm}$ ). 8

3. Comparison of Blood Flow Measurements between Groups (mean $\pm \mathrm{SD}$ in $\mathrm{ml} / \mathrm{min}$ ). 8 
CHAPTER I

EFFECTS OF GRASTON ${ }^{\circledR}$ TECHNIQUE ON BLOOD FLOW IN THE UPPER EXTREMITY

\section{Introduction}

Vascular pathologies such as "dead arm syndrome" and thoracic outlet syndrome are of growing concern in today's overhead athlete. ${ }^{1-5}$ Dead arm syndrome (DAS) was first used by Rowe and Zarins ${ }^{1}$ and is described as sharp pain, weakness, and loss of control of an abducted arm. Causes of DAS can include anterior subluxations of the shoulder, thoracic outlet syndrome, or vascular insufficiency. ${ }^{1}$ Thoracic outlet syndrome (TOS) is also a common problem among the overhead athlete. TOS can be described as a clinical syndrome due to compression of the neural or vascular structures passing through the thoracic outlet. ${ }^{6}$ Commonalities among these two syndromes include the compression of vascular structures leading to abnormalities in blood flow. These abnormalities have been noted to occur in the subclavian, suprascapular, subscapular, posterior humeral circumflex, axillary, and brachial arteries..$^{3-5,7}$

Arterial blood flow decreases have been observed in baseball pitchers when compared to the contralateral limb both at rest and during performance. ${ }^{2,3,8}$ One study identified five athletes with abnormal blood flow in a functional position due to enlarged scalene and pectoralis minor muscles. ${ }^{8}$ During warm-up and game simulated pitching conditions, it was found that all pitchers showed decreased blood flow in the throwing arm when compared bilaterally ${ }^{3}$ and further decreases were noted if the pitcher had a history of subluxation. ${ }^{2}$ 
Surgical procedures are available for these athletes who suffer from vascular insufficiencies, however little conservative treatment has been researched for these conditions.

One conservative treatment that could prove useful for these athletes is instrumentassisted soft tissue mobilization (IASTM). Instrument-assisted soft tissue mobilization has become prevalent in patient care. In general, IASTM, uses a single or set of instruments to aid the practitioner in the treatment of a variety of conditions. ${ }^{9}$ Graston ${ }^{\circ}$ technique (GT) is one form of IASTM. As many as 16,000 clinicians have reported using (GT). ${ }^{9}$ In the fields of sports medicine and athletic training, a large number of these conditions include scar tissue, fascial restrictions, and tendinopathies.

GT utilizes a set of stainless steel instruments with beveled edges that are designed to treat specific areas of the body. In order to administer GT, the clinician must be certified. Previous research has found GT to be successful in decreasing pain, ${ }^{10-17}$ as well as increasing range of motion (ROM). ${ }^{18-22}$

Currently, no research has been conducted looking at GT's effects on blood flow or pectoralis minor muscle length. Using GT as a more controlled form of massage may produce beneficial increases in blood flow in injuries where arterial flow is decreased. By mobilizing and lifting restrictions from the anterior and middle scalenes and pectoralis minor, we hypothesize pectoralis minor length and blood flow will increase. Therefore, the purpose of this study was to look at the effects of GT on brachial blood flow and pectoralis minor length in the healthy individuals. 


\section{Methods}

This controlled laboratory study with randomization investigated the effects of GT on blood flow and pectoralis minor length in healthy participants. The independent variable was group (control, sham, and GT). The dependent variables were changes in pectoralis minor muscle length and blood flow in the brachial artery at rest and in the provocative position from pre- to post-intervention.

\section{Participants}

Sixty healthy subjects ( 27 male, 33 female, age $=21.89 \pm 1.83$ years, height $=173.01 \pm$ $9.26 \mathrm{~cm}$, weight $=72.13 \pm 12.86 \mathrm{~kg}$ ) were recruited for this study. To be included in this study subjects had to be recreationally active, participating in some form of physical activity for at least 30 minutes, 3 times per week. Subjects meeting these criteria were screened for the exclusion criteria. Exclusion criteria included any history of upper extremity surgery, upper extremity injury within 3 months prior to participation or during participation, or known contraindications such as blood clots and other vascular insufficiencies, or sensitivity to manual therapy. Subjects meeting all inclusion and exclusion criteria were randomly assigned to one of three groups; a control group, sham group, and a group treated with GT. The subjects in all groups were measured at baseline, and at the end of each treatment or control condition. All participants signed informed consent and the study was approved by the university's institutional review board.

\section{Procedures}

Each participant attended one testing session lasting approximately 30 minutes. Participants were randomly placed into 1 of 3 groups: control, sham, or GT. Blood flow in two positions and pectoralis minor length were measured. The dominant arm was used for all 
participants and was defined as the arm they prefer to throw a ball with. Each participant then performed a 5-minute warm-up on an arm bike. The warm-up was followed by the assigned intervention and pectoralis minor stretching.

\section{Instrumentation}

A standard tape measure was used to measure pectoralis minor length. Blood flow measurements were taken using a Terason t3000 M-series ultrasound system (Teratech, Burlington, MA). The ultrasound produced a 5-12 MHz linear array and combines the Fusion ${ }^{\mathrm{TM}}$ Processor with a laptop computer for mobility. The processor contains 128 receive beam forming channels for high-resolution imaging. This apparatus was calibrated before testing based on the manufacturers recommendations.

\section{Pectoralis Minor Length Measurement}

To measure the length of the pectoralis minor, participants were standing in a resting position, after marching in place for 10 steps with the test arm at their side. A standard tape measure was used to measure the linear distance between the origin and insertion of the

muscle. The origin was defined as the inferior aspect of the $4^{\text {th }}$ rib, and one finger's width lateral to the sternocostal junction. The insertion was defined as the medial-inferior aspect of the coracoid process. These were marked with a marker for ease of retesting and consistency. The same investigator performed all measurements. This method of measuring pectoralis minor length was found to be reliable $(\mathrm{ICC}=0.942, \mathrm{Cl}=95 \%)$. 


\section{Blood Flow Measurement}

The participant was asked to stand with their arms at their sides as the arm was prepped with ultrasonic gel. The brachial artery was identified medial to the humerus at the midpoint between the elbow and the shoulder. The correct position of the probe was confirmed with the sound of the heart's contraction and the blue and red color on the Doppler screen. The examiner held the probe in place until at least four heartbeats were recorded. The resting position was measured with the participant standing with their arm at their side at 0 degrees of abduction. The provocative position was measured with the participant standing with the arm at 90 degrees of shoulder abduction, 90 degrees of elbow flexion, and external rotation to the first point of resistance noted by the examiner. Reliability was tested a priori and found to have a high intrarater reliability $(\mathrm{ICC}=0.917, \mathrm{Cl}=95 \%)$.

\section{Interventions}

The investigator who performed the treatment was certified in level M-1 training for GT. The GT group received 8 minutes of treatment to the areas of the upper trapezius, scalenes, deltoids, pectoralis major, and pectoralis minor, in that order (Table 1). When restrictions were found in the fascia, muscle, or tendons they were treated accordingly. The restrictions were based on the resonance detected with the scanning instruments. If a restriction was found, a vibration was evident. Verification of restriction removal was based solely on the resonance of the scanning instruments. To ensure consistency, a timer was used to measure treatment duration.

The sham group consisted of the primary investigator, going through the GT treatment sequence of strokes without applying any pressure on the skin with the instruments. The 
instruments were glided over the surface of the skin, careful not to break the skin's contour or allow any indentation from the instrument. The control group had no instruments touching the skin and sat quietly for 8 minutes.

\section{Pectoralis Minor Stretch}

Following the 8-minute intervention, each participant was placed in the supine position, with a foam roller placed longitudinally along the spine. The participant's arms were abducted and externally rotated to $90^{\circ}$ with the elbow also flexed to $90^{\circ}$. The investigator then stabilized the subject's body by placing the hand on the coracoid processes of both shoulders. Then a passive horizontal abduction force was applied to each shoulder. Blood flow in both the resting and provocative positions and pectoralis minor length were re-tested following treatment.

\section{Blinding of Investigators}

The investigator taking the measurements was blinded to the intervention received by each participant. Pre-testing was performed in a private examination room. Only the primary investigator knew which group the participant was assigned. Once the pretest measurements were taken, the participant came into a larger room where the warm-up, treatment, and stretching would be done with the primary investigator. Once that was finished, the participant went back into the private examination room and received posttest measurements for blood flow and pectoralis minor length.

\section{Statistical Analysis}

To control for the small differences in groups at baseline, change scores for all variables were calculated and used for analysis. The independent variable was group and the dependent 
variables were blood flow and pectoralis minor length change scores. Alpha levels were set at .05. All data were analyzed using IBM SPSS 20.0 (SPSS Inc. Chicago, IL).

Table 1. Graston ${ }^{\circledR}$ Technique Treatment.

\begin{tabular}{|c|c|c|}
\hline $\begin{array}{l}\text { Graston- } \\
\text { Technique } \\
\text { Instrument }\end{array}$ & Patient Position & Stroke and anatomical area \\
\hline $\begin{array}{l}\text { GT1, GT4, } \\
\text { and/or GT5 }\end{array}$ & $\begin{array}{l}\text { Seated facing treatment } \\
\text { table with head resting in } \\
\text { hands. } \\
\text { May forward flex, rotate, } \\
\text { or laterally flex cervical } \\
\text { spine as needed. } \\
\text { Release restrictions if } \\
\text { found. }\end{array}$ & $\begin{array}{l}\text { Sweep posterior cervical muscles in all } \\
\text { directions. } \\
\text { May use swivel stroke with GT1 angle on local } \\
\text { restrictions. }\end{array}$ \\
\hline $\begin{array}{l}\text { GT1, GT5, } \\
\text { and/or GT4 } \\
\text { GT3 }\end{array}$ & $\begin{array}{l}\text { Seated with arms resting } \\
\text { on table for support. } \\
\text { Release restrictions if } \\
\text { found. }\end{array}$ & $\begin{array}{l}\text { Sweep and fan lateral cervical area from } \\
\text { acromion process to occiput and back. } \\
\text { Swivel with angle of GT1 over tissue } \\
\text { restrictions. } \\
\text { Strum or J-stroke with GT3 over any restrictions }\end{array}$ \\
\hline $\begin{array}{l}\text { GT5 or GT4 } \\
\text { GT3 }\end{array}$ & $\begin{array}{l}\text { Seated with treatment } \\
\text { arm resting on table in } \\
\text { slight abduction. }\end{array}$ & $\begin{array}{l}\text { Sweep and fan the deltoid in all directions. } \\
\text { Strum, sweep, and J-stroke to isolate and treat } \\
\text { restrictions in area. }\end{array}$ \\
\hline $\begin{array}{l}\text { GT } 5 \text { and/or } \\
\text { GT4 } \\
\text { GT } 3\end{array}$ & $\begin{array}{l}\text { Side-lying or supine on } \\
\text { table with head rotated } \\
\text { away from treatment } \\
\text { side. }\end{array}$ & $\begin{array}{l}\text { Sweep and fan the lateral cervical muscles, } \\
\text { including the scalenes from the acromion } \\
\text { process and clavicle to the occiput and mastoid } \\
\text { process and back. } \\
\text { Strum or J-stroke the superior } \\
\text { sternocleidomastoid. } \\
\text { Gently mobilize restrictions. }\end{array}$ \\
\hline GT4 and GT3 & $\begin{array}{l}\text { Supine on table. } \\
\text { Arm in } A B D, E R \text {, and } \\
\text { varying degrees of } \\
\text { elevation. } \\
\text { Arm neutral or abducted } \\
\text { off the table for pectoralis } \\
\text { minor. }\end{array}$ & $\begin{array}{l}\text { Sweep and fan as much of the pectoralis as } \\
\text { possible. } \\
\text { Sweep and strum pectoralis minor via axilla. }\end{array}$ \\
\hline $\begin{array}{l}\text { GT4 } \\
\text { GT3 }\end{array}$ & $\begin{array}{l}\text { Supine on table with arm } \\
\text { at side or overhead. }\end{array}$ & $\begin{array}{l}\text { Sweep, fan, and scoop biceps and triceps from } \\
\text { origin to insertion. } \\
\text { Strum restrictions if found. }\end{array}$ \\
\hline
\end{tabular}




\section{Results}

Pectoralis Minor Length

Pectoralis minor length was adjusted to the height of each participant. This was calculated by dividing the raw pectoralis minor length by the height of the participant and multiplying by 100 for a percent score. There was no significant difference between the three intervention groups on change scores, $F(2,52)=.219, p=.804$ (Table 2).

Blood Flow

There was no significant difference between the intervention groups on change scores for blood flow taken at the resting position, $F(2,52)=956, p=.390$. There also was no significant difference between the groups in the provocative position on change scores $F(2,52)$ $=2.723, p=.074$ (Table 3). A medium effect size for the GT group compared to the control group was found using Cohen's $d$ for pooled SD with a 95\% confidence interval $(d=0.70, \mathrm{Cl}=0.09$ 1.30).

Table 2. Pectoralis Minor Length Changes between Groups (mean $\pm S D$ in $\mathrm{cm}$ ).

\begin{tabular}{|l|l|l|l|}
\hline $\begin{array}{l}\text { Pectoralis Minor } \\
\text { Length }\end{array}$ & Control (N=21) & Sham (N=15) & GT (N=19) \\
\hline Pre-test & $7.59 \pm 0.63$ & $7.40 \pm 0.77$ & $7.61 \pm 0.76$ \\
\hline Post-test & $7.69 \pm 0.68$ & $7.53 \pm 0.87$ & $7.74 \pm 0.75$ \\
\hline Mean change & $0.10 \pm 0.20$ & $0.13 \pm 0.19$ & $0.14 \pm 0.19$ \\
\hline
\end{tabular}

Table 3. Comparison of Blood Flow Measurements between Groups (mean \pm SD in $\mathrm{ml} / \mathrm{min}$ ).

\begin{tabular}{|l|l|l|l|}
\hline Variable & Control & Sham & GT \\
\hline $\begin{array}{l}\text { Blood Flow Resting position } \\
\text { (pre-test) }\end{array}$ & $24.01 \pm 9.09$ & $21.69 \pm 7.16$ & $26.22 \pm 9.08$ \\
\hline $\begin{array}{l}\text { Blood Flow Resting position } \\
\text { (post-test) }\end{array}$ & $23.26 \pm 8.74$ & $24.40 \pm 6.27$ & $26.57 \pm 9.06$ \\
\hline
\end{tabular}




\begin{tabular}{|l|l|l|l|}
\hline$\%$ Change in Resting position & $-3.11 \%$ & $12.48 \%$ & $1.35 \%$ \\
\hline $\begin{array}{l}\text { Blood Flow Provocative } \\
\text { position (pre-test) }\end{array}$ & $21.58 \pm 7.84$ & $20.55 \pm 6.07$ & $21.10 \pm 8.57$ \\
\hline $\begin{array}{l}\text { Blood Flow Provocative } \\
\text { position (post-test) }\end{array}$ & $21.66 \pm 9.33$ & $23.72 \pm 6.39$ & $26.19 \pm 8.44$ \\
\hline $\begin{array}{l}\% \text { Change in Provocative } \\
\text { position }\end{array}$ & $0.38 \%$ & $15.45 \%$ & $24.11 \%$ \\
\hline
\end{tabular}

\section{Discussion}

The purpose of this study was to compare blood flow and pectoralis minor length changes among GT, sham, and control groups. Previous research has shown that blood flow in the overhead athlete decreases while in the provocative position..$^{2,3,5,8}$ While this decrease in blood flow may be the result of various pathologies, we know that moving the arm into abduction and external rotation causes compression of the axillary artery. ${ }^{5}$ It has been suggested that tightening of the scalenes and pectoralis minor causes this decrease in blood flow. ${ }^{4-8,23}$ Further compression of the artery is caused by an anterior translation of the humeral head while in the throwing position. ${ }^{1,2,24}$

We hypothesized that one session of GT with a warm-up and stretch would acutely affect pectoralis minor length and blood flow. The results indicated that an acute stretch and treatment over the pectoralis minor muscle was not effective in increasing the length of the muscle. Similarly, there were no acute changes to blood flow while in the resting or provocative positions. Various authors have described positional compression in the shoulder as the intermittent occlusion that occurs as a result of the position of the arm. ${ }^{3,5}$ We see this especially with overhead athletes, more commonly pitchers, due to the biomechanics of the sport. Considering the anatomy of the arm during throwing, the arm is brought up to abduction, horizontal abduction, and near maximal external rotation, it is conceivable that the delicate vascular structures may be compressed. During this movement, the clavicle and first rib have 
been shown to move in a scissor-like fashion while the humeral head moves downward resulting in compression of the axillary artery. ${ }^{26}$

The two types of TOS that involve musculature rather than bony abnormalities can also have impact on the blood flow in the shoulder and arm. The first type involves the scalenes, and while it was addressed during the treatment, we chose to focus more on the second type. Hyperabduction syndrome, first described by Wright in 1945, describes the second portion of the axillary artery becoming occluded by the overlying pectoralis minor muscle when the arm is brought overhead. The provocative shoulder position in this study likely caused the pectoralis minor to increase the compressive force on the artery resulting in decreased blood flow. Our results suggest that utilizing a one-time manual therapy session with GT and a gross stretch was not effective in releasing this tension of the muscle, which we hypothesized would improve blood flow in the brachial artery.

The pectoralis minor length did not show significant changes between groups. Therefore, it should be noted that our study shows that one GT and gross stretch does not appear to have any immediate effects on the length of the pectoralis minor muscle. This is contrary to a study that looked at pectoralis minor length changes after either gross or focused stretch. ${ }^{27}$ This study found the gross stretch to be statistically significant compared to control, but found no other significance between any groups. ${ }^{27}$ An explanation for the difference in findings could be the variation in gross stretch methods. Williams et $\mathrm{al}^{27}$ stretched each dominate shoulder unilaterally, while we stretched bilaterally. Additionally, the subjects for each study varied widely with the current study using a healthy population as compared to using collegiate swimmers with prominently rounded shoulders. ${ }^{28}$ The results could vary by using a 
population with known tendencies to rounded shoulders, which typically indicate tightness in the pectoralis minor.

GT has been reported to localize and treat soft tissue restrictions by enabling the clinician to easily detect and treat thickenings, ridges, adhesions, nodules, and scar tissue. ${ }^{9} \mathrm{GT}$ is theorized to produce a localized trauma to the soft tissue producing micro-injury and reinitiates the body's healing response to restore tissue normality. ${ }^{16,29}$ This inflammatory response starts the healing cascade and increases blood, nutrients, and fibroblastic activity in the area, which leads to increased collagen synthesis and tissue maturation. ${ }^{22}$ This response to healing may have caused the moderate increases in blood flow that we saw in the provocative position since we did not see a change in pectoralis minor length. Many studies have shown GT to increase ROM in various joints in the human body, ${ }^{16,30-32}$ but none have shown increases in specific muscle length. This could be due to the acute treatment and measurement, where the GT manual suggests using multiple treatments to see the most benefit. Additionally, there are currently no studies that look at the effects of GT on blood flow. While we found no changes in our measurements with a single session, the effect size was moderate, indicating that a clinically significant change may be present. Further research should be conducted looking at the effects of GT after multiple treatments.

There are several limitations of this study worth discussing. First, the treatment population used was asymptomatic of any neurovascular injury and otherwise healthy. While we did find significant results when looking at blood flow in the provocative position, we cannot report how those with existing pathologies would respond to this treatment. Different results may have been found if we only used those subjects with a predetermined amount of pectoralis minor tightness or looked at the length while in the overhead position. Additionally, this study 
looked only at the acute effects of GT with stretch and cannot conclude if results would vary with multiple treatments. A predetermined GT application was used for each subject in the treatment group, when clinically each patient is treated with GT based on tissue tightness. However, for this study the author treated the same tissues in each patient for 8 minutes, regardless of the variation in restrictions found to ensure consistency between subjects. Further studies are needed to determine the effects of multiple sessions of GT on blood flow and look at a symptomatic population, such as overhead athletes with decreased blood flow.

\section{Conclusion}

A single treatment using GT did not produce a significant increase in blood flow of the brachial artery or pectoralis minor length in the dominant arms of a healthy population. The results of this study indicate that GT, used in a single treatment, does not significantly increase blood flow or muscle length in the arms of asymptomatic shoulders. 
CHAPTER II

\section{REVIEW OF RELATED LITERATURE}

\section{Bony Anatomy}

The neck and shoulder work closely together in the body. Injury to the neck can often affect movement at the shoulder and injury to the shoulder can create pain at the neck. Therefore, it is import to look closely at these structures, along with the elbow, to fully understand problems that arise in these areas. ${ }^{33}$

The neck is composed of 7 cervical vertebrae, which are the smallest and lightest in the spinal column. $C_{1}$ and $C_{2}$ are also known as the atlas and axis, respectively, and do not follow the "typical" structure of cervical vertebrae. $C_{3}-C_{7}$ each have four distinguishing features; an oval body, a short, bifid spinous process (except in $\mathrm{C}_{7}$ ), a large triangular vertebral foramen, and a transverse foramen in each transverse process. $T_{1}$ provides an attachment site to the $1^{\text {st }} \mathrm{rib}$. This rib is clinically important due to the structures that attach and cross it. It has a prominent scalene tubercle for attachment of the scalene anterior muscle. The superior surface also has two grooves on either side of the tubercle for the subclavian artery and vein. Sometimes an additional rib is present superior to the $1^{\text {st }}$ rib, this cervical rib can compress the structures between it and the true $1^{\text {st }}$ rib causing neurovascular compromise. ${ }^{33}$ 
The pectoral, or shoulder, girdle consists of the humerus, clavicle and scapula. The clavicle is a thin, curved long bone that attaches medially to the sternum and laterally to the scapula. The sternal end attaches to the manubrium on the sternum and the acromial end flattens and attaches to the acromion process on the scapula. Each scapula is thin and triangular in shape. It lies on the dorsal surface of ribs 2-7 with three borders. The superior border is the shortest, the medial border is closest to the vertebral column, and the lateral border is thick and contains the small glenoid fossa. The glenoid fossa is a small shallow cavity on the superior and lateral part of the scapula that articulates with the head of the humerus. The posterior surface of the scapula bears a prominent spine that is enlarged laterally at its tip and is known as the acromion. The coracoid process projects anteriorly off the scapula and is an important site for muscle attachments. ${ }^{33}$

The humerus is the sole long bone in the upper arm attaching proximally to the scapula via the glenoid cavity and distally to the ulna and radius. The proximal humeral head sits loosely in the glenoid fossa allowing for great motion. Moving inferiorly is the anatomical neck, greater tubercle and more medially lesser tubercle. The tubercles are separated by the intertubicular or bicipital groove. At the distal end of the humerus are the two condyles, a medial trochlea, and a lateral capitulum. The condyles articulate with the ulna and are flanked by the epicondyles on either side. On the anterior surface, superior to the trochlea, is the coronoid fossa. The olecranon fossa is on the posterior side. Both fossae allow the ulna to freely move into flexion and extension. The radial fossa, lateral to the coronoid fossa, articulates with the radial head when the elbow is flexed. ${ }^{33}$

The forearm is made up of two long bones that run parallel to each other called the radius and ulna. The ulna is slightly longer and is thicker proximally and thinner distally towards 
the wrist. The radius is thin proximally and thick distally. They are connected by ligaments and the interosseous membrane, which becomes important for shock distribution. The olecranon process and coronoid process of the ulna connect with the humerus to make up the elbow. Just distal sits the radial head and neck and the proximal radius. ${ }^{33}$

\section{Bony Articulations}

The shoulder has four major articulations to consider that include: the sternoclavicular joint, the acromioclavicular joint, the glenohumeral joint, and the scapulothoracic joint. The sternoclavicular (SC) joint describes the articulation between the sternum and the clavicle. The joint is stabilized by four ligaments; the anterior and posterior sternoclavicular ligaments, the interclavicular ligament, and the costoclavicular ligament. These ligaments work together to prevent the clavicle from superior or inferior displacement and lateral displacement. The acromiclavicular (AC) joint describes the articulation between the acromion process of the scapula and the clavicle. The AC joint has the anterior, posterior, superior, and inferior ligaments. The clavicle is further stabilized by ligaments between the clavicle and the coracoid process of the scapula. These ligaments are the conoid and trapezoid ligaments. The scapulothoracic joint describes the articulation between the scapula and the thoracic ribs, which is only supported by muscle. ${ }^{34}$

The glenohumeral joint is considered to be the true shoulder joint because it describes the articulation between the humerus and the glenoid fossa of the scapula. The joint is surrounded by a loose, articular capsule that is strongly reinforced by the superior, middle, and inferior glenohumeral ligaments and the strong coracohumeral ligament. The labrum surrounds the glenoid rim and acts as an additional stabilizer of the glenohumeral joint. ${ }^{34}$ 


\section{Soft Tissue Structures}

The muscles acting on the glenohumeral joint can be separated into three groups. The first group of muscles are those that originate on the axial skeleton and attach to the humerus and include the latissimus dorsi and pecoralis major. The second group are those muscles that originate on the scapula and attach to the humerus and includes the deltoid, teres major, and coracobrachialis. In addition the rotator cuff muscles include the subscapularis, supraspinatus, infraspinatus, and teres minor. The biceps brachii muscle also attaches to the humerus and scapula. The last group of muscles attach to the axial skeleton and the scapula and include the levator scapulae, trapezius, rhomboids, and serratus anterior and posterior. These muscles are important in providing dynamic stability to the shoulder complex and aid in achieving full range of motion at the glenohumeral joint. ${ }^{34}$

Blood and Related Soft Tissue

Arteries and veins in the body carry blood from the heart to the tissues of the body and then back to the heart. They form an intricate network that works together to get blood where it is needed most by either vasoconstriction or vasodilation. All blood being pumped out of the heart first runs through the aorta and then branches into different arteries until those become capillaries and then back to veins going to the heart again. ${ }^{33}$

In the upper extremity, the blood travels from the aorta to the right and left subclavian arteries, which travel laterally between the clavicle and first rib, and enters the axilla. The subclavian artery comes into contact with the $1^{\text {st }}$ rib posterior to the anterior scalene muscle and anterior to the middle scalene muscle. The internal thoracic artery braches off the inferior portion of the subclavian artery and descends posterior to the clavicle into the thorax. The 
thyrocervical trunk branches off of the anterior portion of the subclavian artery and gives rise to four branches: suprascapular, transverse cervical, ascending cervical, and inferior thyroid arteries. The suprascapular artery passes inferolaterally over the anterior scalene muscle, crosses over the subclavian artery and brachial plexus, and runs posterior and parallel to the clavicle before passing to the posterior scapula. ${ }^{33}$

At the lateral portion of the $1^{\text {st }}$ rib, as the subclavian artery reaches the axilla it becomes the axillary artery. The axillary artery is comprised of three segments. The first segment lies between the $1^{\text {st }}$ rib and the pectoralis minor muscle. The second segment lies posterior to the pectoralis minor, and the third segment is between the pectoralis minor and the teres major muscles. The axillary artery branches off to the axilla, chest, and shoulder in the form of the thoracoacromial, lateral thoracic, subscapular, and anterior and posterior circumflex humeral arteries. The thoracoacromial artery is deep to the pectoralis minor and supplies the deltoids and pectoral regions with blood. The lateral thoracic artery, another branch of the axillary artery, descends along the axillary boarder of the pectoralis minor and follows it onto the thoracic wall. The subscapular artery runs inferiorly along the lateral boarder of the subscapularis and axillary border of the scapula. Branching off of the subscapular artery is the circumflex scapular and thoracodorsal arteries which supply the scapula and lattisimus dorsi muscle, respectively. The circumflex scapular artery curves around the axillary border of the scapula and enters the infraspinatus fossa and the thoracodorsal artery is simply an extension of the subscapular artery. The anterior and posterior circumflex humeral arteries form a circle around the neck of the humerus. ${ }^{33}$

As the axillary artery emerges from the axilla, it becomes the brachial artery. The brachial artery runs along the medial aspect of the humerus and supplies the flexors of the arm. 
One of its major branches is the deep brachial artery of the arm. The deep brachial artery encircles the elbow joint, suppling much of its nutrition. As the brachial artery crosses the anterior-middle aspect of the elbow it provides an easily palpable pulse before splitting just distally into the radial and ulnar arteries. ${ }^{33}$

\section{Nerve Distribution}

There are 31 pairs of spinal nerves that supply all parts of the body except the head and some parts of the neck. They are a part of the complex peripheral nervous system giving messages of both sensory and motor to the body and brain. The cervical spine contains 8 nerves, due to one above and below $C_{7}$. These nerves come together in the neck and shoulder and are referred to as the brachial plexus. ${ }^{33}$

The large brachial plexus is positioned in the neck and axilla and give rise to all the nerves in the upper extremity. The plexus is formed by the mixing of ventral rami of $C_{5}-C_{8}$ and $T_{1}$, it also at times connects with fibers from $\mathrm{C}_{4}$ or $\mathrm{T}_{2}$ or both. Moving from medial to lateral the plexus branches from ventral rami to trunks, then divisions to cords. The roots or ventral rami lie deep to the sternocleidomastoid muscle and unite together to form the upper, middle, and lower trunks. The trunks then divide almost immediately into anterior and posterior divisions, which pass deep to the clavicle and under the axilla. Then the divisions give rise to three large bundles called the lateral, medial, and posterior cords. Along the plexus, nerves branch off to supply the muscles and skin of the shoulder and superior thorax. ${ }^{33}$

The brachial plexus ends in the axilla and branches into five important nerves. The axillary nerve comes off the posterior cord and runs posterior to the neck of the humerus and innervates the deltoid and teres minor muscles. The musculocutaneous nerve is the major 
branch off the lateral cord and runs through the inferior anterior arm, supplying the biceps brachii and brachialis muscles in the arm. The median nerve runs through the arm anteriorly to the forearm and innervates the flexor muscles of the forearm to flex the wrist and fingers, as well as innervates the pronators. The ulnar nerve arises off the medial cord and runs down the medial arm and forearm. This nerve supplies the flexor carpi ulnaris and part of the flexor digitorum profundus not innervated by the median nerve and also supplies most of the intrinsic muscles of the hand. Lastly, the radial nerve, which is the largest branch of the plexus, is a continuation of the posterior cord. This nerve wraps around the humerus and then runs anteriorly around the lateral epicondyle at the elbow where it divides and runs down the lateral forearm to the hand. It supplies all of the extensor muscles and produces elbow extension, supination, wrist and finger extension, and thumb abduction. ${ }^{33}$

\section{Microanatomy of Muscle and Tendon}

Soft tissue refers to several types of connective tissue in the body: tendons, ligaments, muscle, and fascia. Connective tissue in general is the most abundant and widely distributed tissue in the body. Its locations include the skin, membranes, muscle, bone, nerves, and organs. Connecting tissue to one another in the body, connective tissue forms the supporting framework for the entire body. Connective tissue can be broken down into two main types of fibers: collagen and elastic. There are three main types of collagen fibers. Type III is the weakest of the three and present during tissue healing. Type I collagen is the strongest of the fibers and $90 \%$ of the body contains this type of collagen. Type II is typically only found in cartilage. The fibroblast is the main cell responsible for making collagen. ${ }^{33}$ 
Skeletal muscle is contractile tissue, meaning that it has the ability to shorten. Skeletal muscle is connected to bone via tendons or aponeuroses. The main role of skeletal muscle is to maintain an upright posture and produce movement. Cells of muscle, muscle fibers, are long and thin and contain the contractile components myosin and actin. Each myofibril is surrounded by a sheath called the endomysium. Groups of myofibrils make fiber bundles and are surrounded by perimysium and the entire muscle is covered by the epimysium. The epimysium is the outermost layer of muscle anchoring to tendons at either end. Epimysium is made of tough connective tissue to protect the underlying components. ${ }^{33}$

Injury to these tissues can be debilitating and affect a person's normal movement patterns. The musculoteninous unit in particular, is susceptible to injury due to the large forces applied during eccentric contractions and consists of the muscle, tendon, and the fascia that surrounds that muscle. ${ }^{34}$ Common injuries to muscle include strains, cramps, spasms, and soreness. The most common type of tendon injury seen is tendonitis or tendonosis. ${ }^{35}$ Tendonitis is defined as inflammation of the tendon, where tendonosis is the breaking down of the tendon without inflammation. $^{22,35}$

The last type of musculoskeletal injury to be discussed is myofascial trigger points. Myofascial trigger points are defined as hyperirritable areas in the muscle or fascia that can be felt as a hardened nodule. ${ }^{36,37}$ Two types of trigger points are latent and active. A latent trigger point will not cause pain unless direct pressure is applied, but may restrict motion or cause muscular weakness. ${ }^{36,37}$ An active trigger point will cause pain at rest spontaneously and also restrict motion and cause weakness of that muscle. ${ }^{36,37}$ Active trigger points are most known to patients due to the referred pain caused, usually their chief complaint. ${ }^{37}$ Many times an acute strain of a muscle causes these trigger points and within a few days is repaired on its own. ${ }^{37}$ 
However, when pain or restricted motion is noted due to ongoing trigger points, manual therapy is a common treatment modality performed to alleviate the symptoms.

One common place for myofascial trigger points to occur is within the triceps surae complex. ${ }^{36}$ Trigger points noted in these muscles can cause cramps, referred heel pain, and limited dorsiflexion range of motion (ROM). ${ }^{36}$ Perhaps the most discussed treatment for trigger point therapy is pressure release or ischemic compression, which is described as placing pressure over the nodule until the muscle tension or pain is relieved. ${ }^{36-38}$ The pressure release treatment can be either done by a clinician or in the form of self-treatment with either a foam roller or a ball, such as a tennis ball. Release of trigger points usually results in lengthened sarcomeres and decreased muscle tension, felt almost immediately. ${ }^{36}$ One study ${ }^{36}$ looked at myofascial trigger points in the triceps surae muscle group and performed pressure release over a series of 6 weeks. After discharge the patients showed an average increase in dorsiflexion ROM of 4 degrees. Ninety percent of patients also reported having increased function in their lower extremity at this time.

\section{Improving and Maintaining Flexibility}

Flexibility is defined as the ability to move a joint or joints smoothly and easily through an entire range of motion. ${ }^{34}$ Having a full range of motion is recognized to be essential to not only daily living, but in performance as well. Lack of motion at any one joint can cause compensations at that or other joints in the body. The compensations may at times lead to awkward movements patterns due to a loss of neuromuscular control. ${ }^{34}$ It is still unclear in the literature whether stretching improves performance or decreases parameters of performance 
such as power, strength, and endurance. However, most literature agrees that flexibility reduces risk of injury. ${ }^{39}$

Many factors must be considered when finding a cause of restricted motion at a joint. Skin, more specifically scar tissue, is a common cause of restricted motion, and usually occurs after surgical procedures. The most common cause of restricted flexibility is the muscles and tendons, along with the surrounding fascial sheaths. ${ }^{34}$ When muscles and tendons become restricted, the fibers will not slide past one another smoothly and fully. ${ }^{32}$ Connective tissue surrounding a joint is also subject to contractures limiting motion. A major cause of contractures within ligaments and capsules is a period of immobilization. During immobilization these structures lose their elasticity and shorten, making it hard to gain the range of motion lost. The last cause of restricted motion at a joint is neural tissue tightness. Tightness here could be from compression, repetitive microtrauma, muscular imbalances, joint dysfunction, or poor posture. Irritation of the neural tissue causes pain and inflammation, which in turn causes guarding and altered normal movement patterns. ${ }^{34}$

There are several mechanisms responsible for improved flexibility; neurophysiology/stretch reflex, stretch tolerance, and viscoelastic properties of the stretched muscle. ${ }^{18}$ First, the neurophysiological basis of stretching includes different types of mechanoreceptors. Within the stretch reflex there are muscle spindles and golgi tendon organs. Both types will respond to changes in muscle length, but only the golgi tendon organs respond to changes in muscle tension. ${ }^{18}$ Both mechanoreceptors send sensory impulses to the spinal cord when a muscle is stretched. When the signals reach the central nervous system, a signal is sent back to the spindles sensing the stretch and causing the muscle to contract to resist the stretch. Golgi tendon organs also are sending signals to the spinal cord, and if the stretch lasts at 
least 6 seconds, the golgi tendon organs will override the muscle spindle impulses. When this override happens, the antagonist muscle will relax, allowing further stretch, this relaxation is referred to as autogenic inhibition..$^{34}$ In a similar way the contraction of the agonist group causes relaxation of the antagonist muscle, which is referred to as reciprocal inhibition. ${ }^{34}$

The mechanical properties of muscles and tendons are physically allowing lengthening to occur through neural input. Muscle and tendon are largely composed of collagen and elastin fibers that help to resist deformation or assist in recovery, respectively. Muscle also has contractile components, actin and myosin, also controlling the muscles deformation and recovery. Lengthening a muscle through stretching allows for viscoelastic and plastic changes to occur. $^{34}$

\section{Mechanics and Healing}

Many forms of manual therapy have been used to help relieve pain and increase mobility of musculoteninous structures. Manual therapy historically includes either stretching or compression that is seen in different forms such as joint mobilizations, traction, fascial and tendon stretching, and massage. ${ }^{32}$ No matter the form, manual therapy typically is trying to promote elongation of the soft tissues. However, in order to see permanent changes in the tissue, microfailure needs to occur followed by the normal cycle of inflammation, repair, and remodeling. ${ }^{32}$

The healing process occurs in three phases: the inflammatory response phase, the fibroblastic repair phase, and the maturation-remodeling phase. Once an injury occurs, the cells are damaged and the cellular metabolism changes sending chemical mediators to initiate the inflammatory process. ${ }^{40}$ 
This process is characterized by five signs; redness, swelling, pain, increased temperature, and a loss of function. ${ }^{34}$ This stage of healing is critical for normal healing to take place. After acute inflammation has subsided, the neutrophils are replaced by macrophages, lymphocytes, and fibroblasts. ${ }^{40}$

During the fibroblastic repair phase, proliferation and regenerative activity take place to repair the damaged tissue. ${ }^{40}$ The first part of this phase, fibroplasia begins only a few days after injury and is responsible for beginning scar formations. During this period of scar formations, many signs seen during the inflammatory phase will subside. Formation of connective tissue, called granulation tissue, is made up of fibroblasts, collagen, and capillaries. As the capillaries continue to grow, fibroblasts accumulate and begin to synthesize extracellular matrix. The extracellular matrix consists of protein fibers; collagen and elastin. The fibroblasts produce collagen laid down in random directions, and as the tensile strength of the collagen increase, the number of fibroblasts decrease beginning the maturation phase. ${ }^{34}$

The maturation-remodeling phase is the longest of the three phases emphasizing realignment of the collagen fibers that were laid down. The type III collagen fibers that were laid down during the repair phase turn over to type I collagen, increasing the tensile strength. ${ }^{40}$ These collagen fibers are aligned according to the stresses placed upon that tissue for maximum efficiency against tensile forces. ${ }^{41}$ The scar tissue will begin to look like the normal tissue surrounding the area, but will likely not be as strong as the normal tissue. ${ }^{34}$

If healing does not occur properly or there is left over scar tissue from injury, range of motion can be restricted. Some forms of manual therapy, specifically instrument-assisted soft tissue mobilization (IASTM) or augmented soft tissue mobilization (ASTM), have been shown to 
produce micro-injury in a controlled manner helping to increase fibroblasts. ${ }^{22,40}$ Fibroblasts stimulation is important because it reproduces collagen, elastin, cytokines, and growth factors. ${ }^{41}$ The microtrauma caused by these instruments have been shown to re-initiate the inflammatory process. ${ }^{16,22,40,41}$ Once the inflammatory process has begun, the healing cascade can occur again with the intent in recruiting more fibroblasts and collagen laying down in the correct ways.

\section{Manual Therapy}

Manual therapy has been noted to start as early is the $5^{\text {th }}$ century $\mathrm{BC} .^{42}$ It has been noted that the laying of hands and traction with manipulation has been some of the first forms of manual therapy. In the late 1800 s, a new emphasis on holistic health and preventative medicine emerged. The mid 1900s brought a shift to treatment with a focus on conservative treatment of musculoskeletal disorders. ${ }^{42}$ Today manual therapy is widespread and prevalent in much of the literature.

Massage has long been in the literature and is known to be used as a stand-alone treatment or in conjunction with other forms of therapy. Massage is proposed to decrease pain, increase blood flow and flexibility, and have effects on various psychological factors. ${ }^{42,43}$ However, research has found and disproven each of these claims numerous times. ${ }^{42-45}$

Hinds et al ${ }^{46}$ looked at the effects of femoral blood flow after exercise with massage and found that skin blood flow significantly increased compared to a control group. However, femoral artery blood flow did not seem to be affected, and actually decreased. Although this finding was not significant $(P>0.05)$ it suggests that massage only increases blood flow at the skins surface. Further studies go on to say that the application of massage on one limb, increases blood flow in the contralateral limb. ${ }^{47}$ Other studies agree that massage, in fact, does 
increase peripheral blood flow, even in areas not touched. ${ }^{43,48,49}$ Still, it is inconclusive that blood flow is affected at the muscular level with massage or other types of manual therapy. ${ }^{43}$

Regardless of current findings, massage continues to grow and expand. Currently, instrument-assisted soft tissue mobilizations (IASTM) is one of these trends that has continually increased in the literature. IASTM is based on deep transverse friction massage and ancient forms of Gua Sha. ${ }^{14,16,22}$ Gua Sha originated in Asia and was used to scrape dirt and sweat from the body. ${ }^{22}$ Now Gua Sha is used to promote normal circulation and metabolic processes in the body by creating red petectiae with instruments made of wood, metal, or water buffalo horn. ${ }^{22}$ Deep transverse friction massage, first developed by Cyriax ${ }^{50}$, is based on the theory of creating traumatic hyperemia and preventing adhesions from forming. ${ }^{22,40}$ Both transverse friction massage and IASTM have been found to increase fibroblasts proliferation leading to collagen formation. ${ }^{12,14,22,40,41}$

One of the first studies performed to suggest IASTM would lead to increased healing through fibroblast stimulation was that of Davidson et al. ${ }^{40}$ Another therapeutic technique was used in this particular study known as augmented soft tissue mobilization (ASTM). ASTM uses instruments to provide the contact mobilization forces to treatment areas. ${ }^{40}$ Rat tendons were used and assigned randomly to one of four groups; a control group (A), tendonitis group untreated (B), tendonitis group treated with ASTM (C), and a group only treated with ASTM(D). The results indicated that ASTM would likely improve healing through fibroblast recruitment and improve overall limb function. Activated fibroblasts with developed endoplasmic reticulum were noted in all three groups and not in the control group. This study found that the Achilles tendons treated without induced tendonitis (group D) showed an increase in fibroblast production. The 
authors of this study also concluded that ASTM could promote earlier recovery of limb function evident through the gait analysis data of the injured rats.

Gehlsen et $a^{41}$ looked at how fibroblasts responded to variations in mobilization pressure using rat Achilles tendons. This study randomly assigned the rats into one of five groups; tendonitis only (A), tendonitis with light ASTM (B), tendonitis with medium ASTM (C), tendonitis with heavy ASTM (D), and a control group with surgery only (E). Fibroblast recruitment was evident in groups A-D with groups with heavier pressure having greater numbers of fibroblasts. This study showed that ASTM not only stimulated fibroblast proliferation but that this is a dose-response dependent on the amount of pressure applied by the clinician.

\section{Graston Technique}

Graston Technique (GT) is a prevalent type of instrument-assisted soft tissue mobilizations. GT was introduced to clinical practices in 1994 and is now being utilized by more than 16,000 practitioners today. ${ }^{9}$ Graston offers a specially made set of stainless steel instruments with beveled edges and contours to treat various parts of the body. ${ }^{9}$ This technique of IASTM was designed to help clinicians effectively detect and treat a wide range of soft tissue complications. ${ }^{9,14,19,51}$

GT has been shown to effectively treat a variety of soft tissue pathologies. Currently clinical studies and case series have shown that the use of GT was successful in the treatments of epicondylitis $^{17}$, rotator cuff pathologies ${ }^{22,35}$, Achilles tendonitis ${ }^{20-22,35,40,41}$, and chronic ankle pain $^{16,19}$, and may promote healing to ligaments as seen with healing in the medial collateral ligaments of rats. ${ }^{29}$ 
Research has shown that GT increases the production of fibroblasts, removes scar tissue adhesions, and improves range of motion. ${ }^{14,16,19,22,40,41}$ Currently the research is limited to case studies, animal studies, and only a few clinical studies. No research to date has compared the GT to other forms of IASTM on patient outcomes data. However there are a few studies that compare GT to other forms of therapy. Burke et $\mathrm{al}^{12}$ compared GT to a clinician's hands for the treatment of carpal tunnel syndrome and found no differences in alleviating patients' symptoms. Another study compared two types of IASTM on therapist discomfort and fatigue. ${ }^{51}$ This study used Graston instruments and the metal end of a reflex hammer and found that clinicians who used GT had significantly less discomfort and fatigue, however the treatment time between groups was not different.

There have been several case studies and series reporting success with GT. In a study by Howitt et $\mathrm{al}^{52} \mathrm{GT}$ was found to be successful in treating a posterior tibialis strain when used in combination with other modalities and rehabilitation. Similarly, Howitt et $\mathrm{al}^{15}$ also found that GT successfully treated a patient with unresolved trigger thumb in combination with active release technique. Both studies looked at a single patient's condition and treated the symptoms with multiple modalities and manual therapy techniques. Therefore, it is unclear whether using GT in these case studies was the reason for relief in symptoms. Another case study used Graston instruments to treat subacute lumbar compartment syndrome and found GT and stretching improved the patient's symptoms after 6 visits. ${ }^{14}$ In multiple case studies by Hammer, ${ }^{22}$ GT was found to be successful in treating supraspinatus tendinosis, Achilles tendinosis, and plantar fasciosis. The study sought to review the mechanical deformation load method and found that GT was successful in both detection and treatment of these conditions. 
Other case series have been done that looked at Graston's effects primarily on lower extremity pathologies. In a recent case series White ${ }^{53}$ had success in treating three female distance runners with GT to alleviate their symptoms with high hamstring tendinopathy. In this study all three patients were treated with GIASTM, lumbopelvic manipulation, and electrical stimulation with ultrasound. Rehabilitation focused on hamstring stretching and strengthening, hip strengthening, and balance exercises. All three patients had relief of symptoms on an average of 13 visits, which is longer than a previously mentioned study that used only 6 visits. ${ }^{14,53}$ One case series used 10 patients suffering from plantar fasciitis to determine if GT combined with stretching could alleviate symptoms. ${ }^{31}$ Of particular interest, this case treated the triceps surae, soleus, plantar fascia and medial calcaneal tubercle. The participants were treated a maximum of 8 times, with 6.9 visits being the average. The study found that $70 \%$ of the patients achieved a successful outcome, while $9 / 10$ patients had at least some improvement in symptoms. ${ }^{31}$

Perhaps the only randomized trial using Graston Technique ${ }^{\circledR}$ was done to examine the effects of GT on patients with chronic ankle instability (CAI). ${ }^{19}$ After determining the participants had CAI, they were randomly assigned to 1 of 3 groups. All three groups included a dynamic balance-training (DBT) program and one group used GT, another used a sham treatment, and the third group was a control. The results of this study showed that all three groups had improvements pretest to posttest, with the largest effect sizes for most variables found in the GT and DBT combined group. ${ }^{19}$ 


\section{Vascular Adaptations in the Shoulder}

There are many known problems in the shoulder of the overhead athlete, however, vascular pathologies are of growing concern. In baseball, pitchers were found to have a greater risk of upper extremity injury (2.79 times higher) than position players. ${ }^{54}$ More specifically, various authors have found vascular abnormalities in the shoulders of athletes..$^{2,5,7,8}$ These abnormalities have been found to include the subclavian, suprascapular, subscapular, posterior humeral circumflex, axillary and brachial arteries. ${ }^{3-5,7}$ The majority of literature describes two known pathologies that cause these abnormalities; thoracic outlet syndrome and dead arm syndrome.

Dead arm syndrome (DAS) was described by Rowe and Zarins ${ }^{24}$ as pain, weakness, and loss of control of an abducted arm. They state this syndrome is likely caused by either known or unknown subluxation of the shoulder. During a typical overhead motion, the shoulder is abducted, externally rotated, and extended causing the stresses to be placed on the anterior shoulder and capsule which may lead to subluxation or dislocation. Repetitive overhead throwing or other motions are thought to lead to these subluxations and other vascular pathologies. ${ }^{24}$ Anterior glenohumeral subluxations may be associated closely with muscular and bony hypertrophy and increased external rotation range of motion. ${ }^{1-3}$ Athletes who are thought to have DAS complain of sharp "paralyzing" pain in the arm that simultaneously "goes dead" and they may complain of losing control of the arm. ${ }^{24}$ This becomes problematic for athletes, such as pitchers, that rely on accuracy and velocity of their arms. DAS mimics nerve type pathologies with pain radiating in the anterior and posterior shoulder, arm, and even hand. Other causes of DAS could be thoracic outlet syndrome, brachial plexus injury, cervical disc pathology, rotator cuff tears, or vascular insufficiency. ${ }^{24}$ 
Thoracic outlet syndrome (TOS) is another common pathology that may lead to vascular abnormalities. TOS can be described as a clinical syndrome due to compression of the neural or vascular structures passing through the thoracic outlet. ${ }^{6}$ Types of TOS have been broken into three categories: scalene syndrome, hyperabduction syndrome, and pectoralis minor syndrome. Most commonly the inferior trunk of the brachial plexus is involved because of its location. The trunk is made of rami from C 8 and $\mathrm{T} 1$ and lies above the first rib and behind the subclavian artery. The subclavian artery passes behind the sternoclavicular joint, over the first rib between the anterior and middle scalene muscles, then courses laterally behind the clavicle, continues posteriorly while branching into the axillary and brachial arteries. ${ }^{6}$ The term vascular thoracic outlet syndrome (vTOS) is associated with the subclavian artery due to its common site of compression at either the scalene triangle or the costoclavicular space. ${ }^{7}$ TOS can show with complicated symptoms, but most display some combination of pain localized in the upper body, upper extremity paresthesias, numbness, weakness, heaviness, fatigability, swelling, discoloration, or other neural symptoms. ${ }^{6}$

Regardless of the cause of TOS, athletes may develop arm ischemia secondary to TOS due to the repetitive nature of overhead activities. Contributing factors include hypertrophy of the pectoralis minor and anterior scalene muscles, mechanical compression by ribs, humeral hypertrophy, or glenohumeral subluxations. ${ }^{8}$ Early fatigue of the upper extremity is a common symptom of arterial compromise. ${ }^{8}$ Nuber et al ${ }^{8}$ found that 5 athletes complaining of early fatigue in their upper extremity had normal arterial filling with their arm at their side, but with the arm abducted in a functional position had arterial compromise. They also identified subclavian arterial compression from hypertrophic anterior scalene muscles and compression of 
the axillary artery due to an enlarged pectoralis minor muscle. ${ }^{8}$ All athletes in this study were successfully treated surgically.

Other studies have been conducted that look at the blood flow in the overhead athlete. ${ }^{2-5,7}$ Bast et al $^{2}$ looked further at the effects of shoulder laxity on blood flow in major league baseball pitchers. The authors had the pitchers go through a sequence of pitches, this time 50 consecutive pitches to simulate a bullpen warm-up. Measurements were taken at rest and after the last pitch. They compared the results of those pitchers with known instability to those who had no reports of glenohumeral instability. They found that pitchers with instability only increased $35 \%$ arterial flow from baseline compared to $115 \%$ in pitchers without instability. These results were statistically significant and may suggest that laxity in the shoulder capsule of pitchers further affects blood flow. ${ }^{2}$

Bast et $\mathrm{al}^{3}$ went on to look at changes in arterial and venous blood flow in baseball pitchers' arms during a game simulated condition. Each participant in this study threw 100 pitches, 20 at a time with 6 of those pitches being off speed. Eight measurements of blood flow were taken using doppler ultrasound at rest, after a warm up, after each 20-pitch sequence (to 100 pitches), and one hour after the last pitch. They compared this with the non-dominate arm and found the arterial blood flow increased rapidly throughout the warm-up period and first 40 pitches in the dominant arm. After 60 pitches and continuing through one hour of rest, arterial blood flow decreased in the dominant arm and was recorded to be $42 \%$ below the resting value. The nondominant arm also increased and decreased throughout the pitching sequence but to a much lesser extent. However, neither of Bast et $\mathrm{al}^{2,3}$ studies looked at arterial blood flow in a provocative position like the aforementioned study ${ }^{8}$ which could have further shown decreases in blood flow during pitching. 
Bast et al ${ }^{3}$ states multiple possible causes for this decrease in arterial blood flow of pitchers in a game-like situation. They concluded that the arterial insufficiencies found in this study lead to what is known as the fatigue phenomenon. ${ }^{3}$ One of the possible reasons for transient axillary artery occlusion is compression of a hypertrophied pectoralis minor muscle, which lies directly over top of the second segment of the artery. ${ }^{3}$ This compressive force is further exaggerated by bringing the arm overhead. Pitchers and other overhead athletes may be at an increased risk due to the countless daily repetitions of this overstressed overhead motion. Other authors have found hypertrophic scalene muscles to cause similar compression at the subclavian artery, which could also lead to "dead arm" or the fatigue phenomenon., Additional possible causes of increased arterial compression have been cited to be anterior glenohumeral subluxations and hypertrophy of the humeral head. ${ }^{1,2,5,8}$

\section{Conclusion}

Thus far, no research has looked at GT effects on blood flow. The purpose of this study is to look at GT's effects on blood flow and pectoralis minor length in the upper extremity. We know that blood flow has been found to decrease in volume in the overhead athlete. We also know this change is due to anatomical variations in the bony or soft tissue anatomy. If there are decreases in blood flow due to soft tissue or muscular anatomy, we may be able to increase blood flow. By releasing the restrictions found in the musculature overlaying the delicate neurovascular structures in the shoulder and neck, the blood may flow more freely and increase in volume distally. 


\section{REFERENCES}

1. Rowe CR. Recurrent transient anterior subluxation of the shoulder. the "dead arm" syndrome. Clin Orthop Relat Res. 1987;(223)(223):11-19.

2. Bast SC, Weaver FA, Perese S, Jobe FW, Weaver DC, Vangsness CT,Jr. The effects of shoulder laxity on upper extremity blood flow in professional baseball pitchers. J Shoulder Elbow Surg. 2011;20(3):461-466.

3. Bast SC, Perry JR, Poppiti R, Vangsness CT, Weaver FA. Upper extremity blood flow in collegiate and high school baseball pitchers A preliminary report. Am J Sports Med. 1996;24(6):847-851.

4. Schneider K, Kasparyan NG, Altchek DW, Fantini GA, Weiland A. An aneurysm involving the axillary artery and its branch vessels in a major league baseball pitcher $<\mathrm{br} />\mathrm{A}$ case report and review of the Literature . Am J Sports Med. 1999;27(3).

5. Duwayri YM, Emery VB, Driskill MR, et al. Positional compression of the axillary artery causing upper extremity thrombosis and embolism in the elite overhead throwing athlete. J Vasc Surg. 2011;53(5):1329-1340.

6. Nichols AW. The thoracic outlet syndrome in athletes. J Am Board Fam Pract. 1996;9(5):346355.

7. Stapleton C, Herrington L, George K. Sonographic evaluation of the subclavian artery during thoracic outlet syndrome shoulder manoeuvres. Man Ther. 2009;14(1):19-27.

8. Nuber GW, McCarthy WJ, Yao JS, Schafer MF, Suker JR. Arterial abnormalities of the shoulder in athletes. Am J Sports Med. 1990;18(5):514-519.

9. Graston technique: Simple technology improving injury treatment and rehabilitation. GrastonTechnique.com2013.

10. Bayliss AJ, Klene FJ, Gundeck EL, Loghmani MT. Treatment of a patient with post-natal chronic calf pain utilizing instrument-assisted soft tissue mobilization: A case study. $J$ Manipulative Physiol Ther. 2011;19(3):127-134. 
11. Black DW. Treatment of knee arthrofibrosis and quadriceps insufficiency after patellar tendon repair: A case report including use of the graston technique. Int J Ther Massage Bodywork. 2010;3(2):14-21.

12. Burke J, Buchberger DJ, Carey-Loghmani MT, Dougherty PE, Greco DS, Dishman JD. A pilot study comparing two manual therapy interventions for carpal tunnel syndrome. $J$ Manipulative Physiol Ther. 2007;30(1):50-61.

13. Daniels CJ, Morrell AP. Chiropractic management of pediatric plantar fasciitis: A case report. J Chiropr Med. 2012;11(1):58-63.

14. Hammer WI, Pfefer MT. Treatment of a case of subacute lumbar compartment syndrome using the graston technique. J Manipulative Physiol Ther. 2005;28(3):199-204.

15. Howitt $\mathrm{S}$, Wong J, Zabukovec $\mathrm{S}$. The conservative treatment of trigger thumb using graston techniques and active release techniques. J Can Chiropr Assoc. 2006;50(4):249-254.

16. Melham TJ, Sevier TL, Malnofski MJ, Wilson JK, Helfst RH,Jr. Chronic ankle pain and fibrosis successfully treated with a new noninvasive augmented soft tissue mobilization technique (ASTM): A case report. Med Sci Sports Exerc. 1998;30(6):801-804.

17. Papa JA. Two cases of work-related lateral epicondylopathy treated with graston technique(R) and conservative rehabilitation. J Can Chiropr Assoc. 2012;56(3):192-200.

18. Taylor DC, Dalton JD,Jr, Seaber AV, Garrett WE,Jr. Viscoelastic properties of muscle-tendon units. the biomechanical effects of stretching. Am J Sports Med. 1990;18(3):300-309.

19. Schaefer JL, Sandrey MA. Effects of a 4-week dynamic-balance-training program supplemented with graston instrument-assisted soft-tissue mobilization for chronic ankle instability. J Sport Rehabil. 2012;21(4):313-326.

20. Papa JA. Conservative management of achilles tendinopathy: A case report. J Can Chiropr Assoc. 2012;56(3):216-224.

21. Miners AL, Bougie TL. Chronic achilles tendinopathy: A case study of treatment incorporating active and passive tissue warm-up, graston technique, ART, eccentric exercise, and cryotherapy. J Can Chiropr Assoc. 2011;55(4):269-279.

22. Hammer WI. The effect of mechanical load on degenerated soft tissue. J Bodyw Mov Ther. 2008;12(3):246-256.

23. Burkhart SS, Morgan CD, Kibler WB. Shoulder injuries in overhead athletes. the "dead arm" revisited. Clin Sports Med. 2000;19(1):125-158.

24. Rowe CR, Zarins B. Recurrent transient subluxation of the shoulder. J Bone Joint Surg Am. 1981;63(6):863-872. 
25. Laudner K, Compton BD, McLoda TA, Walters CM. Acute effects of instrument assisted soft tissue mobilization for improving posterior shoulder range of motion in collegiate baseball players. Int J Sports Phys Ther. 2014;9(1):1-7.

26. Durham JR, Yao JS, Pearce WH, Nuber GM, McCarthy WJ,3rd. Arterial injuries in the thoracic outlet syndrome. J Vasc Surg. 1995;21(1):57-69; discussion 70.

27. Williams JG, Laudner KG, McLoda T. The acute effects of two passive stretch maneuvers on pectoralis minor length and scapular kinematics among collegiate swimmers. Int J Sports Phys Ther. 2013;8(1):25-33.

28. Lynch SS, Thigpen CA, Mihalik JP, Prentice WE, Padua D. The effects of an exercise intervention on forward head and rounded shoulder postures in elite swimmers. $\mathrm{Br} \mathrm{J}$ Sports Med. 2010;44(5):376-381.

29. Loghmani MT, Warden SJ. Instrument-assisted cross-fiber massage accelerates knee ligament healing. J Orthop Sports Phys Ther. 2009;39(7):506-514.

30. Draper DO, Anderson C, Schulthies SS, Ricard MD. Immediate and residual changes in dorsiflexion range of motion using an ultrasound heat and stretch routine. J Athl Train. 1998;33(2):141-144.

31. Looney B, Srokose T, Fernandez-de-las-Penas C, Cleland JA. Graston instrument soft tissue mobilization and home stretching for the management of plantar heel pain: A case series. J Manipulative Physiol Ther. 2011;34(2):138-142.

32. Threlkeld AJ. The effects of manual therapy on connective tissue. Phys Ther. 1992;72(12):893-902.

33. Marieb E. Human anatomy and physiology. 7th ed. Pearson-Benjamin Cummings; 2007.

34. Prentice WE. Arnheim's principles of athletic training: A competency-based approach. 13th ed. McGraw-Hill Higher Education; 2009.

35. Sevier TL, Helfst RH, Stover SA, Wilson JK. Clinical trends on tendinitis. Work. 2000;14(2):123126.

36. Grieve R, Barnett S, Coghill N, Cramp F. Myofascial trigger point therapy for triceps surae dysfunction: A case series. Man Ther. 2013.

37. Simons DG, Travell JG. Myofascial origins of low back pain. 1. principles of diagnosis and treatment. Postgrad Med. 1983;73(2):66, 68-70, 73 passim.

38. Simons DG. New views of myofascial trigger points: Etiology and diagnosis. Arch Phys Med Rehabil. 2008;89(1):157-159. 
39. Park DY, Chou L. Stretching for prevention of achilles tendon injuries: A review of the literature. Foot Ankle Int. 2006;27(12):1086-1095.

40. Davidson CJ, Ganion LR, Gehlsen GM, Verhoestra B, Roepke JE, Sevier TL. Rat tendon morphologic and functional changes resulting from soft tissue mobilization. Med Sci Sports Exerc. 1997;29(3):313-319.

41. Gehlsen GM, Ganion LR, Helfst R. Fibroblast responses to variation in soft tissue mobilization pressure. Med Sci Sports Exerc. 1999;31(4):531-535.

42. Smith AR,Jr. Manual therapy: The historical, current, and future role in the treatment of pain. ScientificWorldJournal. 2007;7:109-120.

43. Weerapong P, Hume PA, Kolt GS. The mechanisms of massage and effects on performance, muscle recovery and injury prevention. Sports Med. 2005;35(3):235-256.

44. Barlow A, Clarke R, Johnson N, Seabourne B, Thomas D, Gal J. Effect of massage of the hamstring muscle group on performance of the sit and reach test. Br J Sports Med. 2004;38(3):349-351.

45. Wiktorsson-Moller M, Oberg B, Ekstrand J, Gillquist J. Effects of warming up, massage, and stretching on range of motion and muscle strength in the lower extremity. Am J Sports Med. 1983;11(4):249-252.

46. Hinds T, McEwan I, Perkes J, Dawson E, Ball D, George K. Effects of massage on limb and skin blood flow after quadriceps exercise. Med Sci Sports Exerc. 2004;36(8):1308-1313.

47. Goats GC. Massage--the scientific basis of an ancient art: Part 2. physiological and therapeutic effects. Br J Sports Med. 1994;28(3):153-156.

48. Sefton JM, Yarar C, Berry JW, Pascoe DD. Therapeutic massage of the neck and shoulders produces changes in peripheral blood flow when assessed with dynamic infrared thermography. J Altern Complement Med. 2010;16(7):723-732.

49. Wiltshire EV, Poitras V, Pak M, Hong T, Rayner J, Tschakovsky ME. Massage impairs postexercise muscle blood flow and "lactic acid" removal. Med Sci Sports Exerc. 2010;42(6):1062-1071.

50. Cyriax J. Deep massage. Physiotherapy. 1977;63(2):60-61.

51. Hayes DA, Loghmani MT, Lubitx R, Moore E. A comparison of 2 instrument-assisted soft tissue mobilization techniques: Effects on therapist discomfort/fatigue and treatment time. J Orthop Sports Phys Ther. 2007;37(1):17.

52. Howitt S, Jung S, Hammonds N. Conservative treatment of a tibialis posterior strain in a novice triathlete: A case report. J Can Chiropr Assoc. 2009;53(1):23-31. 
53. White KE. High hamstring tendinopathy in 3 female long distance runners. J Chiropr Med. 2011;10(2):93-99.

54. Posner M, Cameron KL, Wolf JM, Belmont PJ,Jr, Owens BD. Epidemiology of major league baseball injuries. Am J Sports Med. 2011;39(8):1676-1680. 